\title{
Slide Classification: A Historical Survey
}

The historical background of slide collections is treated, with bibliographic references. The major portion of the paper reports and analyzes some of the data derived from a 1968 questionnaire directed to institutions having slide collections.

${ }^{6} \mathrm{~T}$ IE NAME 'LIBRARY' has lost its etymologic meaning and means not a collection of books, but the central agency for disseminating information, innocent recreation or, best of all, inspiration among people. Whenever this can be done better, more quickly or cheaply by a picture than a book, the picture is entitled to a place on the shelves and in the catalog.

“. . . A generation ago the lantern slide was little known except in magic lantern entertainments, and it required some courage for the first schools to make it a part of the educational apparatus. Today there is hardly a college or university subject which is not receiving great aid from the lantern. No one thinks of it as a course in art or discusses it from an ethical standpoint. It is needed by the engineer, physician, botanist, astronomer, statistician, in fact in every conceivable field, but of course, it is specially adapted to popular study of fine arts because they are so dependent on visual examples, and the lantern is the cheap and ready substitute for costly galleries."

Melvil Dewey ${ }^{1}$

Slides, like other nonbook materials, are being liberated from the garrets of libraries and are beginning to share the limelight with books in the literature and

Mrs. Irvine is Assistant Fine Arts Librarian and Supervisor of the Photograph and Slide Collection, Fine Arts Library, Indiana University. at professional gatherings. During 1969 alone, two periodical publications appeared. ${ }^{2}$ In addition, several important studies which will result in formal publications are now in progress, including the Metropolitan Museum of Art's "Classification System," and the "Universal Slide Classification System with Automatic Indexing" developed at the State University of California at Santa Cruz. ${ }^{3}$ Slide curators and librarians also took their places at professional meetings: the College Art Association's Annual Meeting in Boston; and the Institute for Training in Librarianship entitled, "Art Libraries: Their Comprehensive Role in Preserving Contemporary Visual Resources" held at the State University of New York at Buffalo from June 16 to June 20, 1969. Mrs. Florence S. DaLuiso, Art Librarian of the Harriman Art and Music Library, was the Director of the Institute. As its title implies, the Institute focused on the problems inherent in art libraries, be they book- or nonbook-oriented, and the multifarious ways in which humanists utilize these collections. An entire day was devoted to the topic of slide collections-their organization and operation-in which Eleanor Collins, Curator, Slide and Photograph Collection, Department of the History of Art, University of Michigan; Mrs. Luraine Tansey, Slide Librarian, State Uni- 
versity of California at Santa Cruz; and the present writer participated. The following report was delivered at the Institute by the present writer.

In an earlier publication, the present writer discussed the nature and purpose of the study in progress. In order to clarify the comments to follow, a brief recapitulation is necessary. In August of 1968 , a comprehensive study, including a survey of the history of slide collections, their present status, and various practical and formal library procedural matters was undertaken. One product of this study will be the publication of a comparative study manual "so that slide librarians and curators might have a choice of various systems and procedures currently in practice, that they might have some background knowledge, and finally, that they might have a sense of community with others facing problems similar to theirs. The proposal of an 'ideal' system is not the aim of the study, since most users of such a study will be working from already existing collections which have probably grown to such proportions that a complete revision would not be feasible." 4

\section{HistoricAl BACKGROUND}

The earliest noted slide collections date from the 1880s and include the Chicago Art Institute, Cornell University, Dartmouth College, the Metropolitan Museum of Art, Princeton University, the University of Illinois, and the University of Michigan. It was not until 1884 that George Eastman patented the roll film system; collections begun prior to this time depended upon the lantern slide, which is a $3^{1 / 1} 4^{\prime \prime} \times 4^{\prime \prime}$ glass slide with glass used as the medium upon which the image was printed. Many lantern slides were hand painted and were works of art in their own right. In many collections today, the familiar lantern slide, which dates back to the seventeenth century, is still in active use and is particu- larly preferred by the older faculty members. ${ }^{5}$ In quite a few of the older collections, the lantern slide vs the $2^{\prime \prime}$ x $2^{\prime \prime}$ or $35 \mathrm{~mm}$ slide controversy is still raging and will be mentioned later in the context of the literature and questionnaires.

In the 1930s, color dye processes were perfected by Leopold D. Mannes and Leopold Godowsky, Jr., in collaboration with the Kodak Research Laboratory. The result of this work was the introduction of the Kodachrome three-color film process. It was not until the perfection of this particular technique that $35 \mathrm{~mm}$ color slides were widely accepted.

As a consequence of these new developments, the controversy between the merits of the color $35 \mathrm{~mm}$ slide and the black and white lantern slide began appearing in the literature at this time. In 1943 , art historians argued the issues in two articles appearing in the College Art Journal. ${ }^{6}$ Although over twenty years old, these articles have meaning today because slide librarians and curators are still faced with using lantern slides, buying them, or producing them (on roll film). The physical format of these older slides allows for easy hand viewing, but creates storage problems because they require two-thirds more space than $2^{\prime \prime} \times 2^{\prime \prime}$ slides. $^{7}$ In addition, separate projection facilities are required because most projection systems are not readily adaptable to both sizes. Moreover, the rarity of literature on this topic makes a solution rather elusive.

Until the 1960s, the literature was somewhat sporadic and far from comprehensive. The decade of the $1950 \mathrm{~s}$ produced nine articles, three of them dealing with slide production. ${ }^{8}$ An area that is yet to be dealt with in a satisfactory manner for slide curators and librarians is that of color control which is extremely crucial to art history slide collections. This very problem has been one of the major contributing factors in the schism between users of black and 
white as opposed to color slides. Classification system studies have also suffered from the dearth of literature, with only a few published attempts available at clarifying systems presently in use. ${ }^{9}$ Moreover, until 1969, although many classification systems were available upon request from individual institutions, such systems had not yet actually been published. As a courtesy to these schools and museums (and to lighten the burden of their postage and duplication costs), use should be made of the Bibliographic Systems Center (BSC) at the School of Library Science at Case Western Reserve University where a special collection of classification systems and subject heading lists in almost every field are administered. According to the official notifications by the BSC, "A book guide to this collection, 'The Bibliography of Selected Material in Classification,' compiled by Barbara Denison, is being published and copies may be obtained from the Special Libraries Association." What has been especially needed, however, is a philosophy for slide classification and cataloging, not merely a recitation of the details of a particular system which happens to function adequately for one particular situation.

The 1970s propitiously forecast insights into solutions for critical slide collection issues. As mentioned earlier, the development of a "Universal Slide Classification System with Automatic Indexing" at the State University of California at Santa Cruz has been a hallmark in terms of significant publications. ${ }^{10}$ Perusal of a preliminary edition of this work is enlightening not only in terms of its ramifications for the future of slide collections both in scientific and humanistic disciplines, but also as a meaningful, though brief, essay on slide cataloging and classification philosophy. In addition, the Metropolitan Museum of Art's "Classification System" by Priscilla Farah, and that at the University of Minnesota by Dimitri Tselos are both to be published in the near future. Another publication in progress is Guidelines for the Organization and Administration of Audio-visual Materials by the ACRL Audio-visual committee of ALA.

\section{Present Study}

As can be gathered, providing a patron with high quality material in a meaningful arrangement and providing the slide librarian with adequate data to do so are not simple tasks. To ease the burden, the present study was undertaken. In August of 1968, 112 questionnaires ("Slide Library Comparative Study Questionnaire") were mailed to college, university, and a select number of museum slide collections. In December 1968, 61 follow-up letters were mailed to institutions that had not yet responded. ${ }^{11}$

The inadequacies of such an initial study are overwhelming because of the very nature of starting from a base of zero in terms of the establishment of mailing lists, the lack of standardized terminology, and the determination of the scope or limitations of such a project. Because there has never been an attempt to define precisely the various operations and procedures practiced in slide collections, it was quite difficult to write a questionnaire that could be understood in exactly the same manner by everyone reading and answering it. In order to compensate for this lack of accepted vocabulary, the format of the questionnaire was in outline form with an attempt to include all possible variations and explanations of operations so that the respondee could merely check the most appropriate answer or, in a limited number of cases, fill in a blank. Even this format was not totally satisfactory, and consequently, the interpretation and tabulation of each questionnaire often produced erratic statistical correlation.

The total number of questionnaires 
tabulated as of this report is 65 . The total number of responses to the questionnaire is 80 . This latter figure includes the following breakdown: eight collections too small to merit inclusion in the study (distinction made by the person who did not answer the questionnaire); five institutions that stated nonexistence of a collection; and two institutions which sent descriptive letters of collections rather than answering the questionnaires. ${ }^{12}$ Thus, 71 percent $(80)$ of the original 112 institutions responded to a request for information regarding their facilities.

Although an attempt was made initially to set a limitation on the size of the collection included in the present study, the base of 25,000 was dropped because not all sources consulted gave the exact sizes of slide collections; also, because of the tremendous growth rates of many collections, it seemed unfair to omit collections under such an arbitrary standard. Consequently, the frequent lack of such data coupled with the desire to include as many academic collections as possible negated the use of a size-limitation factor for the inclusion or exclusion of slide collections in this study.

The following section of this report indicates the similarities and differences in slide collections and the subsequent trends that have occurred as noted in the questionnaires tabulated thus far. A brief description of each of the seven sections of the questionnaire will be followed by a discussion of the answers calculated on both a numerical and a percentage basis.

Section I of the questionnaire dealt with questions regarding the history of collections, i.e., date of origin, purpose of collection, and the type of staff in charge of the collection at its inception. Although audiovisual materials in libraries have only recently come to the fore as a serious study source, they have been a fairly steady and consistently occurring phenomenon in art history depart- ments. Over the past seventy years, only the 1940s and the 1950s witnessed a significant rise in the initial development of these collections. This increase is very likely due to the fact that this period marked the widespread use of $2^{\prime \prime} \times 2^{\prime \prime}$ or $35 \mathrm{~mm}$ slides which were pointed out in the literature of the time as being considerably less expensive than the standard lantern slides. These trends might also have been indicative of the steady rise of art historical studies as more than a mere humanities adjunct to liberal arts education in the United States.

In most art history departments, the slide collection has been developed to serve solely the art department; therefore, it is not surprising that 57 percent (36) of these collections were facultyrun when first started, as compared to the 17 percent (11) which were initially organized and staffed either by an individual with a graduate library degree (M.L.S.) or a master's degree in art history.

Section II of the questionnaire concentrated on varieties of classification systems in use. As would be expected due to the origin of these collections, 58 percent (38) of the systems presently in use are based upon a historical chronology and style arrangement with various modifications of subdivisions within this format. In lieu of the notation vs absence-of-notation controversy surrounding slide collections, 29 percent (19) of the institutions responded that they have a system using some form of decimal notation. Only five of these nineteen collections began after 1940. In addition, two of the institutions in the survey noted that they were dropping a notation system-one of these includes the Fogg Museum Collection of Harvard University which is no longer using it for their $2^{\prime \prime}$ x 2" slide collection.

If the arrangement of the collections beginning in the last thirty years is used as a guide, then it is possible that there has been a trend away from a specific 
type of decimal or numerical notation system for slide collections. There are, however, two schools of thought in this matter. The factor of cost involved in the cataloging and classifying of individual slides, coupled with the capability of their rapid production or purchase by institutions have probably contributed in the movement away from a complicated notation scheme and toward a more simplified labelling method based upon some type of alphabetical abbreviation system. It is possible, however, that automatic indexing or computer applications might change the trend in this area.

The two classification systems most commonly used as a basis for other collections are the Metropolitan Museum of Art's scheme and the Fogg Art Museum's scheme. Approximately 22 percent (14) of the collections noted that their classification systems were borrowed from these institutions. As expected, 35 percent (23) of the systems were based on faculty requests. The remainder were personally devised by the original staff or had unknown origins.

Section III of the questionnaire included slide production and expansion operations presently practiced in slide collections. Questions on the production and purchase of $35 \mathrm{~mm}$ and lantern slides, the growth rate, types of film used, and the basis for commercial orders were listed. The preference by some art historians for lantern slides over the $2^{\prime \prime} \times 2^{\prime \prime}$ slide is still unresolved, as 22 percent (14) of the institutions responded that they are presently engaged either in making or buying lantern slides. Needless to say, the size of the image does contribute to the quality of a projected image, but then again, so does the clarity of the original image that has been copied in order to make slides. Many slides are reproduced from books or are copied from master slides (if purchased) thereby being several times removed from the quality of the original image. It should be noted that of the fourteen schools still involved in adding lantern slides to their collections, only two began their collections after 1935 .

As mentioned earlier, it was difficult to pinpoint collections of a specific size in advance of mailing the questionnaires. The resulting broad range of collections makes it difficult to generalize in regard to average weekly or yearly production figures. For example, a very small collection might be expanding at a greater yearly rate than a more established collection. The latter can be more selective in its slide acquisition pattern because it already has a core collection of basic art historical monuments to support its clientele's demands. At the same time, if a department is faced with a great deal of faculty or staff turnover and with the installation of new courses or frequent curriculum changes, the collection encounters a more rapid growth than might be predicted by its actual size. Consequently, no attempt will be made to make any gross generalizations about growth rates; if information on specific institutions or regions is desired, figures may be supplied upon request.

Another critical area in slide acquisition policies is whether or not to buy slides commercially. Such purchases are often quite expensive, particularly in light of the comparative absence of qualitative guides which would allow for knowledgeable discrimination when selecting dealers and their material. Most responsible dealers, however, usually send material on approval. As far as can be ascertained, only a handful of listings are available to the slide curator. The present writer's knowledge of such lists has been acquired over a period of three years through correspondence and, in two cases, through a literature search..$^{13}$ In fact, 80 percent (52) of the institutions in the study base their commercial purchases not solely upon lists but upon previous experience with particular dealers. One question specifically asked for 
previous knowledge of a formal listing prepared and distributed upon request by the Metropolitan Museum of Art and entitled, "Sources of Slides Illustrating the History of Art." This list is probably the most comprehensive and reliable source for commercial and museum slide dealers in the United States and Europe. Of the 65 institutions responding, 26 percent (17) had no knowledge of this list.

Section IV of the questionnaire involved the use of standard library tools or techniques used by slide libraries. The results of this section were indicative of the fact that most slide curators and librarians are fairly sophisticated users of library tools and that the title "slide library" might be a more informative and valid nomenclature than "collection."

An inventory check system is an invaluable aid to slide collections in the same manner that it is to book collections. Separate or interfiled shelflists are the two types used in slide libraries. An interfiled shelflist refers to the placement of a shelflist card in front of or behind each slide in a drawer storage case. Of the collections polled, 55 percent (36) have either an interfiled or a separate shelflist.

Although 40 percent (26) of the collections did not have an authority file of all artists and architects included in their slide holdings, 53 percent (35) relied on the Thieme-Becker Lexikon of artists, along with other aids to verify names. ${ }^{14}$ Twenty-nine percent (19) however did have separate authority files for painters and 31 percent (20) maintained a separate authority file for architects. Of the 65 collections, 25 percent (16) maintained authority files for both painters and architects. Forty percent (26) depended upon faculty recommendations to make entry decisions for artists' and/or architects' names within their files. Such files are quite critical to the efficient organization of a slide collection because, without an authority which is consistently and readily utilized for name entries, a single artist may be filed under a variety of names and countries, thereby dispersing his works chaotically throughout the slide files.

Another type of check system useful in slide collections is the source file or accession record. Only 21 percent (14) make no allowance whatsoever for this technique, which requires source data for each slide to be printed directly upon the slide or to be printed in a supplementary record form. Because many slides are copied directly from plates in books, a source file can function as a bibliographic aid referring a patron to specific texts relating to the slide image.

Generally speaking, slide collections are beginning to take their place with the ranks of book libraries in terms of their utilization of similar tools and techniques on a level that should in the future become even more indicative of the ways in which these collections work in conjunction with an art library. For further information on the interrelationship between slide collections and art libraries, the reader is referred to an excellent article by Frederick Cummings ${ }^{15}$

Section V dealt with circulation methods currently practiced in slide collections. Only 17 percent (11) took no measures at all to supervise the circulation of slides. The most common check-out system used is charge-sheets (sheets on which a patron lists each slide individually giving either a full subject description or only accession or alphabetical code numbers) with 43 percent (28) utilizing this technique. Because of the heavy faculty use patterns, the application of stringent circulation methods is rather difficult, i.e., the feasibility of checking out thirty to forty or more slides for a single lecture often prohibits a slide curator or librarian from asking the patron to comply with involved check-out procedures for individual slides. Consequently, the art history faculty or staff may not be utilizing the 
charge-sheet method but another simpler check-out technique, such as interfiled color code cards (each faculty or staff member has a discrete color card which replaces the slide he has removed and is usually placed in back of the slide's interfiled shelflist card).

Section VI covered questions on storage and projection systems for slide collections. A rather high percentage, 52 percent (34), of the collections in this study still have enough lantern slides to merit the use of double projection systems to compensate for the size difference between $2^{\prime \prime} \times 2^{\prime \prime}$ and $33^{1 \prime \prime} \times 4^{\prime \prime}$ slides. Twenty-eight percent (18) of the institutions, however, are in the process of duplication of their lantern slides onto $2^{\prime \prime} \times 2^{\prime \prime}$ or $35 \mathrm{~mm}$ slides.

Specialized equipment for audiovisual material and especially for slide collections has been slow in developing, but there has been satisfaction noted in some areas in this particular study. Fifty-seven percent (37) of the institutions indicated that the desired efficiency had been reached for storage facilities for slides. Only 35 percent (23) were equally satisfied with their projection systems. Not all slide libraries, however, maintain and purchase their own projectors. In some instances, the audiovisual department handles this aspect of the slide collection facilities.

Section VII of the questionnaire examined the present staffs of slide collections. As noted earlier, 57 percent (36) of these collections were facultyrun when first initiated as opposed to 17 percent (11) which were organized and staffed by an individual with either an M.A. in art history or an M.L.S. in library science. Of the 57 percent (36) which were faculty-run originally, about one-third are now staffed by an individual with an M.A. or an M.L.S. ${ }^{16}$ Another third of these 36 collections are now staffed by individuals with undergraduate degrees (who are usually considered clerical) with the remaining third still under faculty supervision, maintained by M.F.A. graduates or by individuals without a college degree.

Another promising indication of the changing status of slide collection staffs is the fact that 47 percent (29) of the 65 institutions are staffed presently with individuals having either an M.L.S., an M.A. in art history, or an M.L.S. plus an additional graduate degree. In addition, 23 percent (15) of the respondents indicated an interest in elevating their staffs from a clerical to a professional level. In many instances, the mere realization or recognition that there is a problem marks the first step toward change.

Not all subsections of the questionnaire have been discussed. Queries and criticisms will be gladly entertained because the total picture is a twofold matter relying both on specific data and on liberal dialogue among those seeking to make slide collections "libraries," and not merely masses of material.

\section{REFERENCES}

1. Melvil Dewey, "Library Pictures," Public Libraries 11:10 (1906).

2. Betty Jo Irvine, "Slide Collections in Art Libraries," College \& Research Libraries 30:443-45 (Sept. 1969); Elizabeth M. Lewis, "A Graphic Catalog Card Index," American Documentation 20:238-46 (1969).

3. "Classification System for Slides," Information Retrieval and Library Automation 3:9 (1968); Wendell W. Simons and Luraine C. Tansey, A Universal Slide Classification System with Automatic Indexing (Santa Cruz, California: The University Library, University of California, 1969). (A Preliminary Edition which is out-of-print.)

4. Irvine, "Slide Collections," p.444.

5. Alfred Guenther, "Slides in Documentation," UNESCO Bulletin for Libraries 17:157 (1963).

6. Philip C. Beam, "Color Slide Controversy," College Art Journal 2:35-38 (1943); James M. Carpenter, "Limi- 
tations of Color Slides," Ibid., p.38 40 .

7. Shirley Ellis, "Thousand Words About the Slide," ALA Bulletin 53:529-32 (1959).

8. Richard Bibler, "Make an Art Slide Library," Design 56:105ff (1955); L. B. Bridaham and C. B. Mitchell, "Successful Duplication of Color Slides; Results of Research at the Chicago Art Institute," College Art Journal 10:26163 (1951); Ellis, "Thousand Words," p.529-32; P. L. Moeller, "Slide and Photographic Services of the Museum of Modern Art," Special Libraries Association (Conference, 41st, Atlantic City; proceedings, June 12-16, 1950), p.77-79; L. F. Perusse, "Classifying and Cataloguing Lantern Slides," Journal of Cataloguing and Classification 10:77-83 (1954); Phyllis A. Reinhardt, "Photograph and Slide Collections in Art Libraries," Special Libraries 50: 97-102 (1959); Dimitri Tselos, "A Simple Slide Classification System," College Art Journal 15:344-49 (1958); Lester C. Walker, Jr., "Low Cost Slide Production for Teaching Aids," College Art Journal 13:39-41 (1953); Lester C. Walker, Jr., "Slide Filing and Control," College Art Journal 16:325-29 (1957).

9. P. Harvard-Williams and S. Watson, "The Slide Collection at Liverpool School of Architecture," Journal of Documentation 16:11-14 (1960); L. E. Kohn, "A Photograph and Lantern Slide Catalog in the Making," $\mathrm{Li}$ brary Journal 57:941-45 (1932); B. W. Kuvshinoff, "A Graphic Graphics Card Catalog and Computer Index," American Documentation 18:3-9 (1967); Elizabeth M. Lewis, "A Graphic Catalog Card Index," American Documentation 20:238-46 (1969); E. Louise Lucas, "The Classification and Care of Pictures and Slides," ALA Bulletin 24:382-85 (1930); Perusse, "Classifying and Cataloguing," p.7783; Simons and Tansey, "A Universal Slide"; E. Swann, "Problems Involved in Establishing a Slide Collection in the School of Architecture, School of Melbourne," Australian Library Journal 9:159-62 (1960); Tselos, "A Simple Slide," p.344-49; Walker, "Slide Filing and Control," p.325-29; Brenda White, Slide Collections: A Survey of Their Organisation in Libraries in the Fields of Architecture, Building, and Planning (Edinburgh, 21 Morningside Gardens: Brenda White, 1967).

10. Simons and Tansey, "A Universal Slide."

11. As of this writing, approximately 30 institutions have been added to the original figure, and questionnaires are still being received.

12. The reason for the institutions stating the nonexistence of a collection is not readily explainable as reliable directories (American Art Directory, American Library Directory, and the Directory of Special Libraries and Information Centers) were used to establish a mailing list.

13. Sandra A. Kocher, " $2 \times 2$ Color Slides of Art," Art Journal 23:42ff (1963); "Where to Find Lantern Slides; a List of Distributors," College Art Journal 5: 137-39 (1946).

14. Ulrich Thieme, Allgemeines Lexikon der Bildenden Künstler von der Antike zur Gegenwart (Leipzig: E. A. Seeman, 1908-1954).

15. Frederick Cummings, "Art Reference Library," College \& Research Libraries 27:201-06 (May 1966).

16. The institutions which noted this transition include the following: Arizona State University; Brooklyn College of the City University of New York; Princeton University; University of California at Berkeley; University of Illinois; University of Iowa; University of Michigan; University of Minnesota; University of North Carolina; University of Oregon; University of Pennsylvania; University of Pittsburgh; and the University of Texas. 